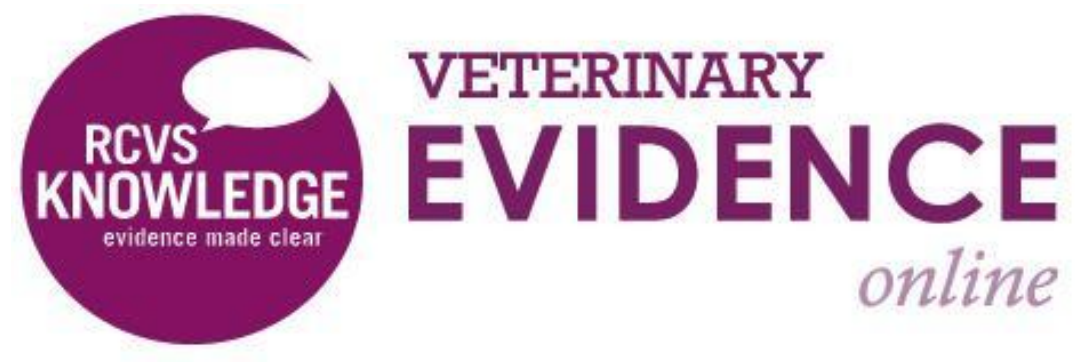

\title{
Is Alpha-casozepine Efficacious at Reducing Anxiety in Dogs?
}

\author{
A Knowledge Summary by \\ Louise Anne Buckley PhD, RVN ${ }^{1 *}$ \\ 1 Harper Adams University, Edgmond, Newport TF10 8NB \\ * Corresponding Author (Ibuckley@harper-adams.ac.uk)
}

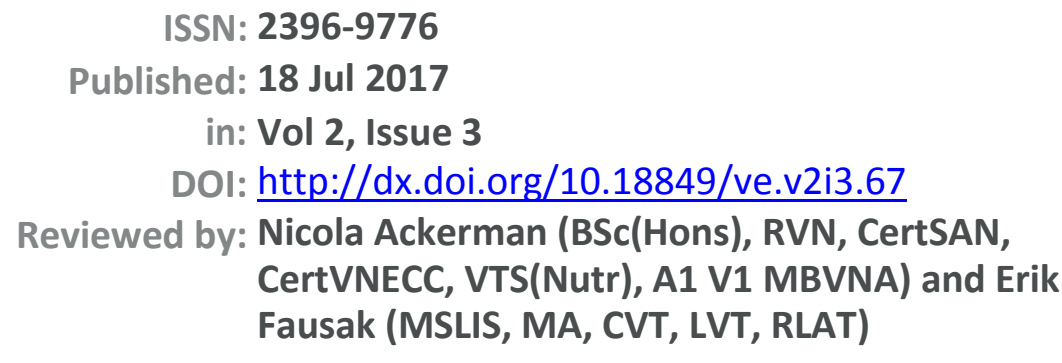

Next Review Date: 18 Jul 2019 
KNOWLEDGE SUMMARY

\section{Clinical bottom line}

There is currently no evidence to show that alpha-casozepine is effective as an anxiolytic when administered to dogs shortly (minutes to a few days) before exposure to an anxiety provoking stressor. There is limited and weak evidence to suggest that it may have a role to play in reducing anxiety in dogs over the medium to longer term but the available evidence is of low quality and / or high risk of bias, with confounding variables providing alternative explanations for the findings. More research is needed in this area.

\section{Question}

Do anxious dogs administered alpha-casozepine show reduced signs of anxiety compared with dogs not administered alpha-casozepine?

\section{Clinical Scenario}

The veterinary team are reviewing the products that they keep within the practice for use in supporting clients whose dogs are anxious for various reasons. They realise that they have never examined the evidence for the use of alpha-casozepine in relation to canine anxiety. However, they have been widely recommending products that contain it, and have had mixed reports back from clients who have used it, so are curious about its efficacy. Thus, they decide to find out how strong the research evidence base is for this biomolecule.

\section{The Evidence}

The Three peer reviewed papers were identified that either partially or fully addressed the PICO. Two of these studies (Palestrini et al., 2010; Kato et al., 2012) investigated the use of diets with added alphacasozepine, though, in the Kato et al. (2012) study the diet was also supplemented with another compound (tryptophan) thought to have anxiolytic properties. The remaining study (Beata et al., 2007) investigated the use of a daily capsule of alpha-casozepine. The two studies focused on dietary interventions (Palestrini et al, 2010; Kato et al., 2012) used a placebo-controlled study design, whereas Beata et al. (2007) compared alphacasozepine to another intervention (selegiline) that was already used commercially as an anxiolytic.

There is no evidence that alpha-casozepine has any effect on canine anxiety in the short term (e.g. when exposed to fireworks or another short acting stressor) or when administered a few minutes to a few days before exposure to potential stressor. All of the studies focus on the potential anxiety-reducing effects of alpha-casozepine when administered in the medium to long term. There was some evidence that alphacasozepine may reduce anxiety as, where effects exist, the direction of effect is always a reduction in the level of whatever parameter was used to measure anxiety. However, the evidence available is low quality. Despite being clinical trials, experimental design and / or data handling was weak, with confounding variables affecting interpretation of the findings. There is a need for better quality research that specifically investigates the use of alpha-casozepine as an anxiolytic in the scenarios that practices would commonly promote its use for. 


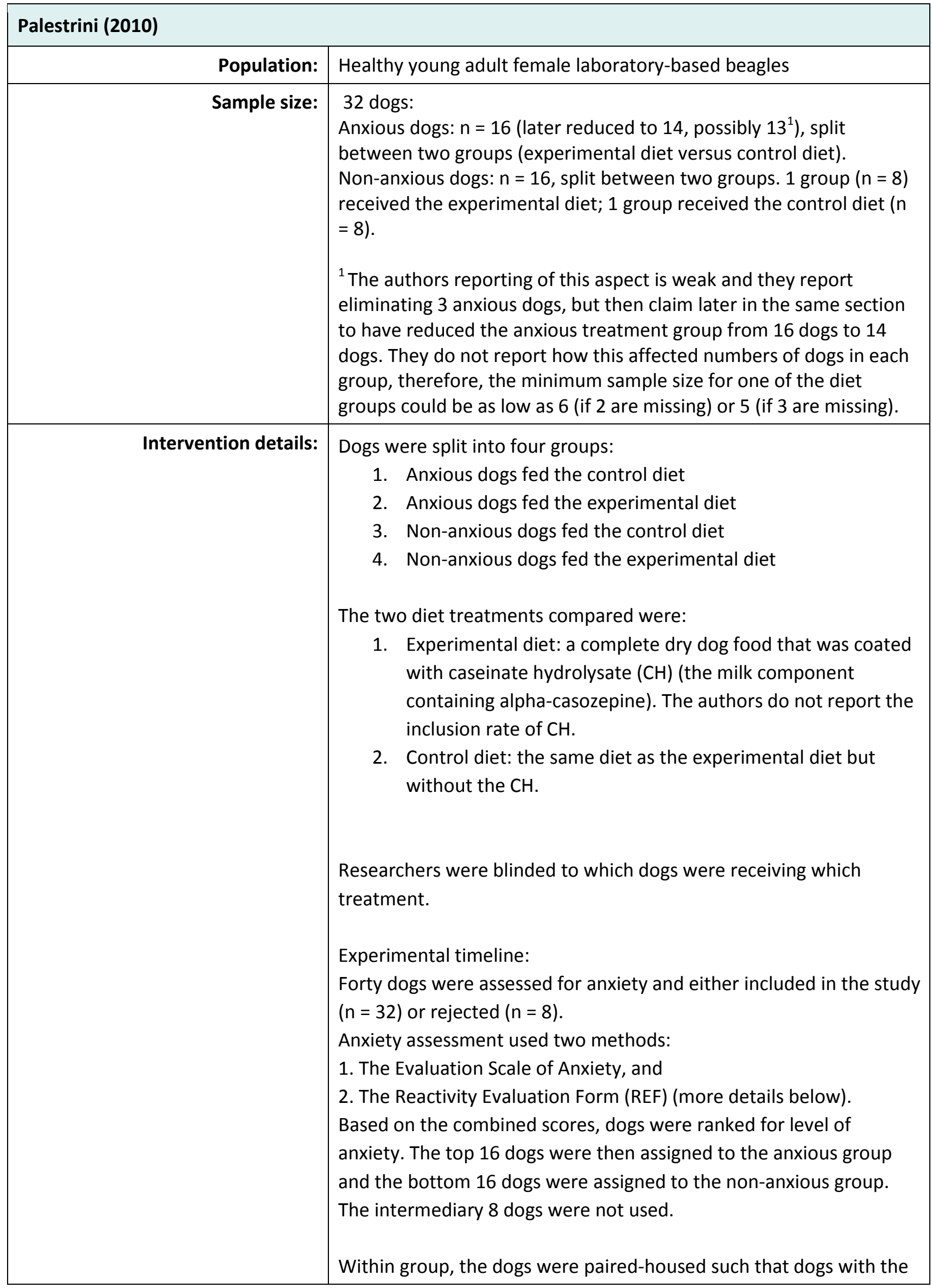




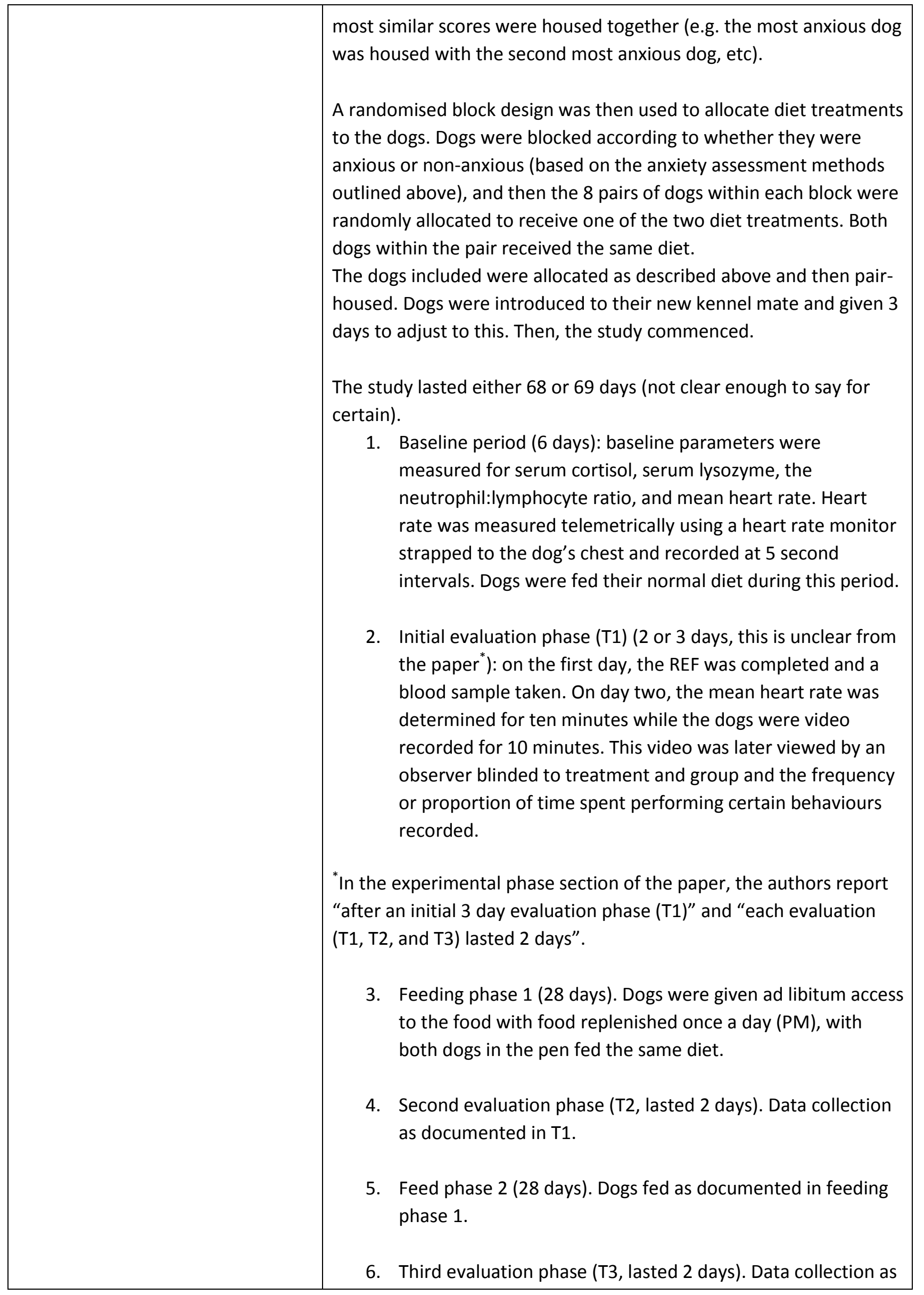




\begin{tabular}{|c|c|}
\hline & $\begin{array}{l}\text { documented in T1. } \\
\text { Initial assessment of anxiety (to select dogs): } \\
\text { 1. Evaluation scale of anxiety: a subjective assessment of } \\
\text { anxiety in which dogs were observed and scored from } 1 \\
\text { (low) - } 6 \text { (high). } \\
\text { 2. REF. A two part objective behavioural assessment, } \\
\text { comprising an ordinal scale of anxiety level (score 1-4) and } \\
\text { the presence of various clinical signs of anxiety (e.g. lick lip: } \\
\text { yes / no, score } 1 \text { point if yes) based on the dogs response to } \\
\text { handler presence outside and inside the test pen. } \\
\text { Both assessment tools were developed by the researchers of this } \\
\text { study. } \\
\text { Two experienced handlers familiar with the dogs independently } \\
\text { assessed the dogs using these two assessment methods and then } \\
\text { agreed the final score per dog. }\end{array}$ \\
\hline Study design: & Randomised clinical trial \\
\hline Outcome studied: & $\begin{array}{l}\text { Behavioural outcome measures: } \\
\text { 1. REF } \\
\text { 2. Proportion of time spent performing various behaviours in } \\
\text { the test pen over } 10 \text { minutes (exploration; locomotion, } \\
\text { passive behaviour, orientated to the environment, } \\
\text { scratching, oral behaviour, vocalisation, play, panting, } \\
\text { grooming) } \\
\text { 3. Frequency of behaviours performed while in the test pen for } \\
\text { 10 minutes (yawning, lip - licking, elimination, drinking, } \\
\text { eating) } \\
\text { Physiological parameters: } \\
\text { 1. Heart rate } \\
\text { 2. Cortisol } \\
\text { 3. Neutrophil: lymphocyte ratio } \\
\text { 4. Lysozyme } \\
\text { It is not clear whether plasma or serum cortisol and lysozyme was } \\
\text { measured as the authors report the terms interchangeably. }\end{array}$ \\
\hline $\begin{array}{l}\text { Main findings: } \\
\text { (relevant to PICO question): }\end{array}$ & $\begin{array}{l}\text { No significant differences were found between the baseline period } \\
\text { data and the initial evaluation phase (T1) data, so the authors used } \\
\text { T1 as their baseline data period. } \\
\text { Behavioural outcome measures: } \\
\begin{aligned} \text { 1. REF: } \\
\text { - At the start (T1), anxious dogs had significantly higher } \\
\text { REF scores than non-anxious dogs (Mann-Whitney U } \\
\text { - Test, } P<0.001) \text {. } \\
\text { - At the start (T1), there was no significant difference }\end{aligned}\end{array}$ \\
\hline
\end{tabular}




\begin{tabular}{|c|c|c|}
\hline & 2. & 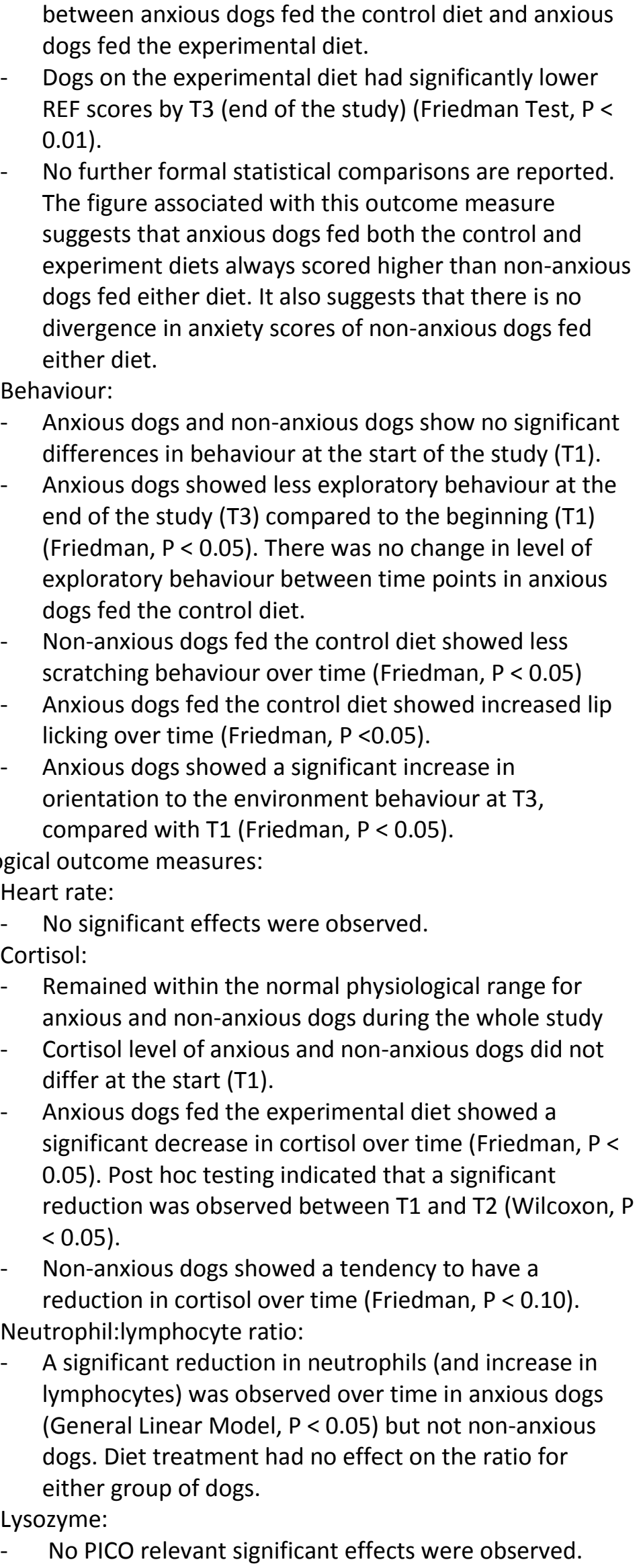 \\
\hline Limitations: & \multicolumn{2}{|c|}{ The authors fail to report the inclusion rate for caseinate } \\
\hline
\end{tabular}


hydrolysate (containing alpha-casozepine) in the diet (g/kg/Dry matter).

The dogs were fed ad libitum during the study so the dose rate would have varied between dogs.

Laboratory population in which the breeding life experiences of the dogs were homogenised and tightly controlled. This contrasts to a pet population and may limit extrapolation of the findings to the wider population of dogs.

The authors undertook a discriminant analysis to retrospectively (after all the data was collected) eliminate dogs whose REF score did not accurately predict which dogs were identified as anxious through the Evaluation Scale of Anxiety (or vice versa, it is not clear which). As a consequence, 2 or 3 anxious dogs were removed. The authors fail to report how this affected the sample size of anxious dogs in the control diet and experimental diet groups respectively. Given the low sample sizes within each group $(n=8)$, this has implications for the interpretation of any findings or extrapolation to the wider population. This is compounded by the wide degree of variation observed (where standard deviations are reported). Retrospective removal of such a large proportion of the sample size for a group should also be questioned.

The authors fail to report the measure of central tendency used to report the REF and cortisol data, and do not provide any measure of variation around this central tendency.

The authors do not provide enough information to interpret the cortisol findings. They report that anxious and non-anxious dogs' cortisol levels did not differ at T1, but do not report the findings for the subgroups relevant to the treatments (especially anxious dogs fed the experimental diet versus anxious dogs fed the control diet). Eyeballing the figure presented suggests that these two sub-groups might vary at the start and combining this data would have increased the variation associated with the anxious group data and made it more difficult to pick out significant differences. However, the lack of error bars makes it difficult to draw many inferences here.

The authors report appears to use the convention of using $\mathrm{P}<0.01$ (tendency) $\mathrm{P}<0.05$ (significant), $\mathrm{P}<0.01$ and $\mathrm{P}<0.001$ (highly significant). It would have been useful to see the exact $P$ value associated with each finding as most appear to be $P<0.05$. The way that they have analysed the behavioural data that they have reported suggests that there may have been many statistical tests performed and this increases the likelihood of a type 1 error (finding a significant finding where one does not exist).

The ethogram derived behavioural data is very problematic to interpret: 


\begin{tabular}{|c|c|}
\hline & $\begin{array}{l}\text { The authors report the findings using mean ( } \pm \text { standard } \\
\text { deviation) which implies the data is normally } \\
\text { distributed. However, they analyse this data using non } \\
\text { parametric tests (Friedman test, with post-hoc testing } \\
\text { via the Wilcoxon test) which implies the data is not } \\
\text { normally distributed. The error bars suggest that there } \\
\text { was a large amount of variation associated with the } \\
\text { performance of some behaviours. } \\
\text { The authors do not provide enough information for } \\
\text { readers to be able to draw their own conclusions about } \\
\text { what the behavioural data may indicate. It would have } \\
\text { been useful to see the descriptive statistics reported for } \\
\text { all the ethogram data, broken down by both treatment } \\
\text { diet and anxiety group. } \\
\text { The authors appear to have cherry picked which } \\
\text { behavioural outcome comparisons to report and key } \\
\text { comparisons (e.g. between anxious dogs fed the control } \\
\text { diet and anxious dogs fed the experimental diet) are } \\
\text { largely missing. } \\
\text { It is not immediately clear that changes between some } \\
\text { of the behaviours in the ethogram would represent a } \\
\text { change in the level of anxiety. }\end{array}$ \\
\hline \multicolumn{2}{|l|}{ Beata (2007) } \\
\hline Population: & $\begin{array}{l}\text { Pet dogs with anxiety-related disorders } \\
\text { The inclusion criteria was as follows: } \\
\text { - At least } 3 \text { months old } \\
\text { - Weigh between } 1.5-42 \mathrm{~kg} \\
\text { - Diagnosed with a behavioural complaint related to anxiety } \\
\text { - At the first visit, the dog scored above } 19 \text { (out of a maximum } \\
\text { of } 45 \text { ) on the Emotional Disorders Evaluation in dogs scale } \\
\text { (EDED) (as used by Pageat, 1995). } \\
\text { Dogs were excluded if: } \\
\text { - The problem had been present for less than four weeks } \\
\text { - There was any evidence that the problem was caused by } \\
\text { - disease, illness or injury. } \\
\text { - Any psychotropic medications had been administered in the } \\
\text { previous two weeks } \\
\text { If the dog scored less than } 20 \text { on the EDED scale. }\end{array}$ \\
\hline Sample size: & $\begin{array}{l}\text { Forty dogs started the trial, } 38 \text { dogs completed it. Two dogs died } \\
\text { (one per treatment) during the study for unrelated reasons } \\
\text { (accidents). }\end{array}$ \\
\hline Intervention details: & $\begin{array}{l}\text { Two treatments (19 dogs per treatment) were compared: } \\
\text { 1. Behavioural modification therapy (BMP) plus oral alpha- } \\
\text { casozepine }(15 \mathrm{mg} / \mathrm{kg} / 24 \mathrm{hrs}) \\
\text { 2. BMP plus oral selegiline hydrochloride }(0.5 \mathrm{mg} / \mathrm{kg} / 24 \mathrm{hrs}) \\
\text { Study design: } \\
\text { - Multi-centre trial that utilised } 7 \text { certified veterinary }\end{array}$ \\
\hline
\end{tabular}




\begin{tabular}{|c|c|}
\hline & 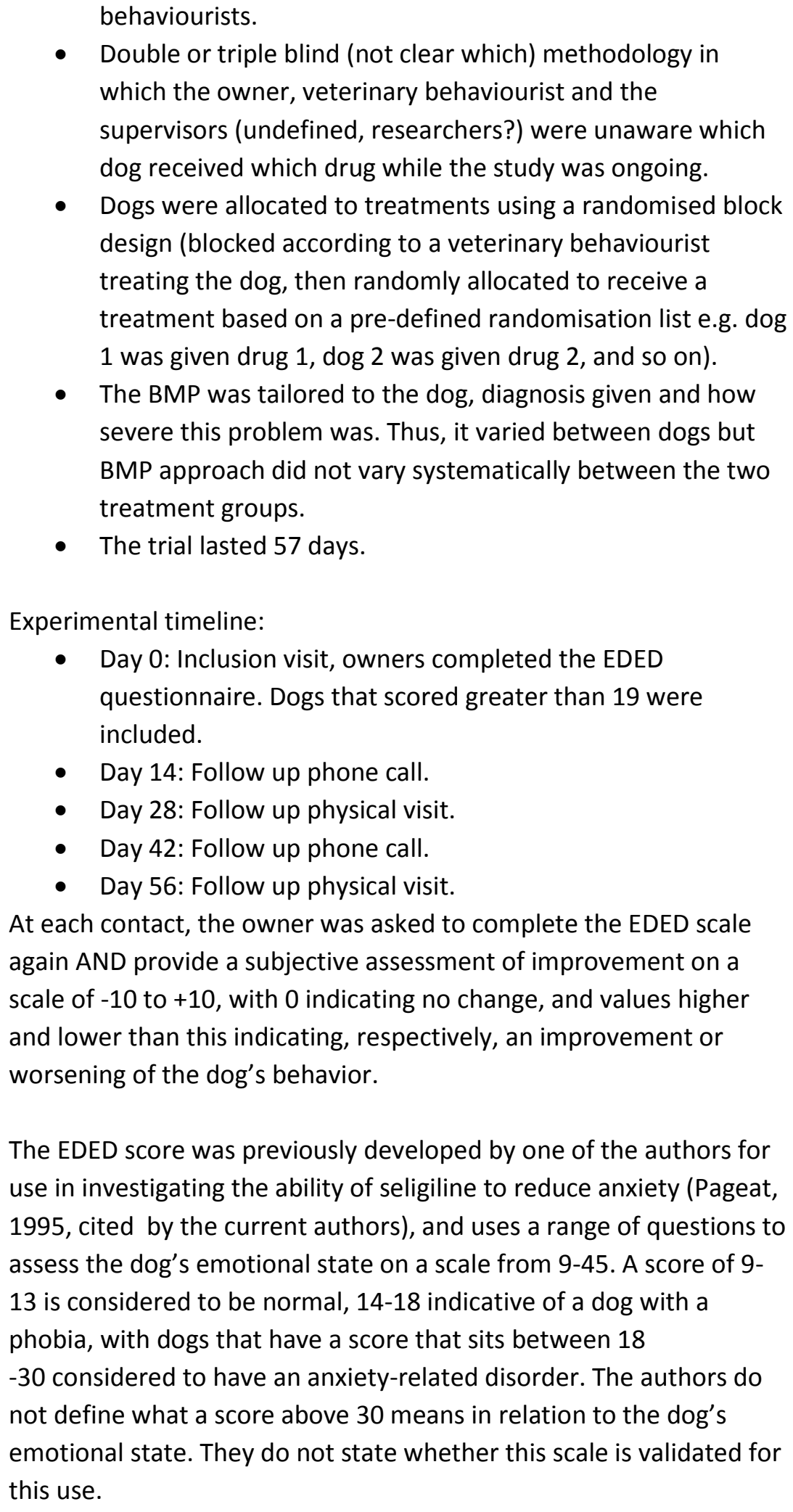 \\
\hline Study design: & Randomised clinical trial \\
\hline Outcome studied: & $\begin{array}{l}\text { The outcome studied at each time point was: } \\
\text { - EDED score } \\
\text { - Owner subjective assessment of improvement }\end{array}$ \\
\hline
\end{tabular}




\begin{tabular}{|c|c|}
\hline & $\begin{array}{l}\text { The authors also introduced a binomial outcome (success / failure of } \\
\text { treatment) "success" measurement. This was based upon the dog } \\
\text { achieving two things: } \\
\text { 1. An EDED score of }<20 \text {, and } \\
\text { 2. An owner subjective assessment of improvement score of } \geq \\
+6 \text {. }\end{array}$ \\
\hline $\begin{array}{l}\text { Main findings: } \\
\text { (relevant to PICO question): }\end{array}$ & 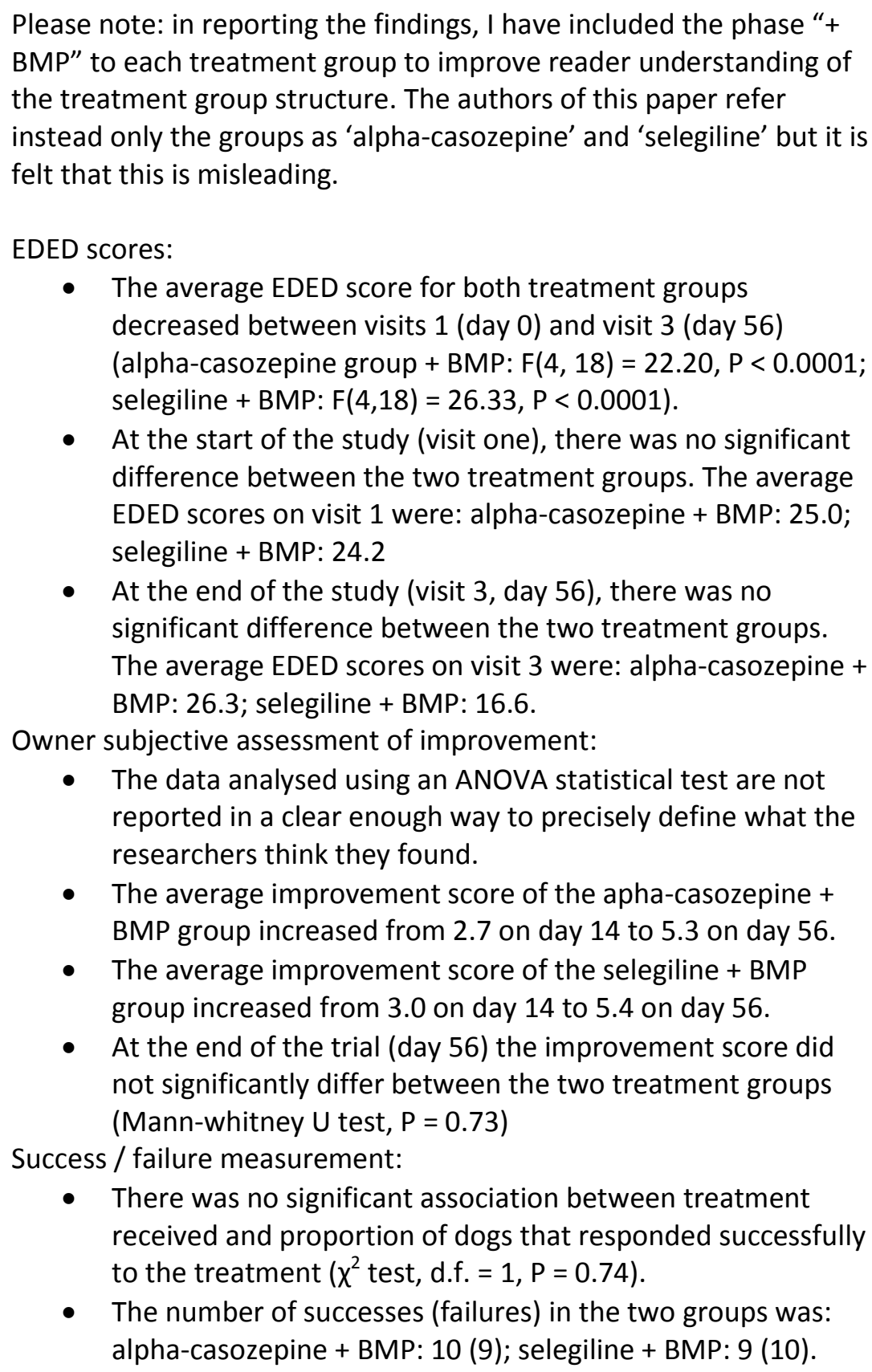 \\
\hline Limitations: & $\begin{array}{l}\text { The study was funded by Ingredia SA (Arras, France). Ingredia is a } \\
\text { company producing milk products and value-added bioactive } \\
\text { compounds related to milk. It is not stated whether the funder had } \\
\text { input into the study design but its authors report that, during data } \\
\text { collection, only the sponsor knew which dog received which } \\
\text { treatment during the trial. }\end{array}$ \\
\hline
\end{tabular}


There was no BMP only treatment group and / or BMP + placebo group.

The paper cited by the authors (Pageat, 1995) is in French so it is not possible to use this paper to better understand the usage of the EDED scale in relation to assessment of selegiline.

The authors do not make clear what they mean by average. Were they presenting medians or means? They do not report any measures of variation (e.g. standard deviation, inter-quartile range, standard error of the mean).

The authors switch between using parametric and non-parametric tests to study aspects of the same data. They do not report any information to indicate that they considered the underlying distribution of the data.

Statistical output reported for the between treatment group pairwise comparisons at visit 1 (day 0 ) and visit 3 (day 56) is unclear as only one $P$ value is reported $(P=0.79)$ for both results.

Technically, the authors cannot make the claim reported in the EDED scores section (that scores decreased between visits one and three for each treatment group) because they only appear to have carried out an ANOVA. The degrees of freedom indicate that they fitted 5 time points (presumably physical visits $1-3$, and telephone calls $1-2$ ). However, no post hoc test has been carried out to identify between which two (or more) pairs of time points the significant difference(s) arises between. Eyeballing the graphical data suggests that a significant difference was most likely between visit 1 and 3 , but this is complicated by the lack of variation reported. This criticism also applies the ANOVA analysed aspect of the owner subjective assessment of improvement scores.

The reporting of the ANOVA analysis for the owner subjective assessment of improvement scores is not clear enough. It is assumed that they are comparing four time points (physical visits 23 , telephone visits $1-2$ because of the degrees of freedom reported) but they do not include enough information.

The claims that are made throughout the research paper are misleading and introduce a potential interpretation bias on the part of the reader with limited research methodology knowledge. The authors consistently refer to the two groups as alpha-casozepine and selegiline, but make limited mention of the fact that these dogs all also received a behaviour modification programme, with no mention at all in the results or conclusion (there is no discussion section). Despite this major confounding variable, the authors make statements like:

"both compounds were equally efficacious" (results), "both products were efficient to decrease the EDED score" (abstract), "due to this efficacy.... Alpha-casozepine (Zylkene) should be considered an 


\begin{tabular}{|c|c|}
\hline & $\begin{array}{l}\text { option by the veterinary surgeon for the biological management of } \\
\text { anxiety" (abstract), etc. } \\
\text { These claims cannot be made given the lack of an adequate control } \\
\text { group as each compound could be equally efficacious at having no } \\
\text { impact on anxiety (i.e. the BMP was the successful component). }\end{array}$ \\
\hline \multicolumn{2}{|l|}{ Kato (2012) } \\
\hline Population: & $\begin{array}{l}\text { Healthy adult small-medium ( } 1.4-12.6 \mathrm{~kg}) \text { pet dogs that scored as } \\
\text { 'anxious' on the Canine Behavioural Assessment \& Research } \\
\text { Questionnaire (C - BARQ). Both genders were included and a } \\
\text { variety of ages and breeds. } \\
\text { Dogs were excluded if they: } \\
\text { - Were pregnant } \\
\text { - Less than one year of age } \\
\text { - Had had a medical condition (i.e. not necessarily current) } \\
\text { aimed at treating behavioural problems (i.e. psycho-active } \\
\text { drugs) }\end{array}$ \\
\hline Sample size: & $\begin{array}{l}44 \text { dogs were recruited to the study. } 28 \text { dogs completed the study. } \\
4 \text { dogs were lost to follow up during the study; the others } \\
\text { withdrew for reasons unconnected to the trial (health issues } \\
\text { of the dogs or personal circumstances of the owner). }\end{array}$ \\
\hline Intervention details: & $\begin{array}{l}\text { The two diet treatments compared for their effects on indices of } \\
\text { canine anxiety in a crossover, single-blind, single order trial were: } \\
\text { 1. Control diet (Royal Canin Select Skin Care Vets Plan) } \\
\text { 2. } \\
\text { acid tryptophan and alpha-casozepine (Royal Canin Calm Canine) } \\
\text { - The alpha-casozepine inclusion rate was } 1.35 \mathrm{~g} / \mathrm{kg} \text { dry matter } \\
\text { (DM), to provide dogs with a dose of approximately } \\
\text { 20mg/kg/day (the recommended dose for dogs under } 15 \mathrm{~kg} \text { ). } \\
\text { - The tryptophan content of the experimental diet was } \\
\text { 3.04g/kg DM (the control diet contained } 2.83 \mathrm{~g} / \mathrm{kg} \mathrm{DM).} \\
\text { - The diets were not identical in all other respects. All the } \\
\text { nutritional components reported differed in inclusion rate. } \\
\text { The dogs were retained in their home environment } \\
\text { throughout the study and fed by their owner (who was } \\
\text { blinded to the treatment they were feeding their dog). } \\
\text { The experimental timeline is as follows: } \\
\text { - The owners of potential canine participants completed a C- } \\
\text { BARQ questionnaire. Dogs that scored as anxious ( } \mathrm{n}=44 \text { ) } \\
\text { were included in the trial. } \\
\text { Dogs received the control diet for } 8 \text { weeks. They were fed } \\
\text { twice a day. Data collection took place in week } 7 \text { (see below } \\
\text { for outcome measures) and comprised completion of the C - } \\
\text { BARQ questionnaire to assess behavioural indices of anxiety } \\
\text { and two urine samples collected to assess urinary cortisol }\end{array}$ \\
\hline
\end{tabular}




\begin{tabular}{|c|c|}
\hline & $\begin{array}{l}\text { levels. One sample was taken in the home environment } \\
\text { (baseline, unstressed measurement) and one sample was } \\
\text { taken } 2 \mathrm{hr} \text { post vet clinic visit (the 'stressed' measurement). } \\
\text { - Dogs then received a } 1 \text { week wash out period. The diet fed } \\
\text { during this period is not stated and is assumed to be the } \\
\text { dog's normal diet. } \\
\text { - Dogs then received the experimental diet for } 8 \text { weeks. All } \\
\text { other details are the same as for the control diet phase. } \\
\text { Further details: } \\
\text { - The wash out period length was determined by a prior } \\
\text { preliminary experiment using high-pressure liquid } \\
\text { chromatography which demonstrated that the dietary } \\
\text { additives would be entirely removed from the dogs systems } \\
\text { within one week. } \\
\text { Cortisol analysis was carried out in duplicate. } \\
\text { - Urine collection was carried out at the same point of day to } \\
\text { reduce the risk of time of day effects on cortisol production. }\end{array}$ \\
\hline Study design: & Experimental cross-over trial \\
\hline Outcome studied: & 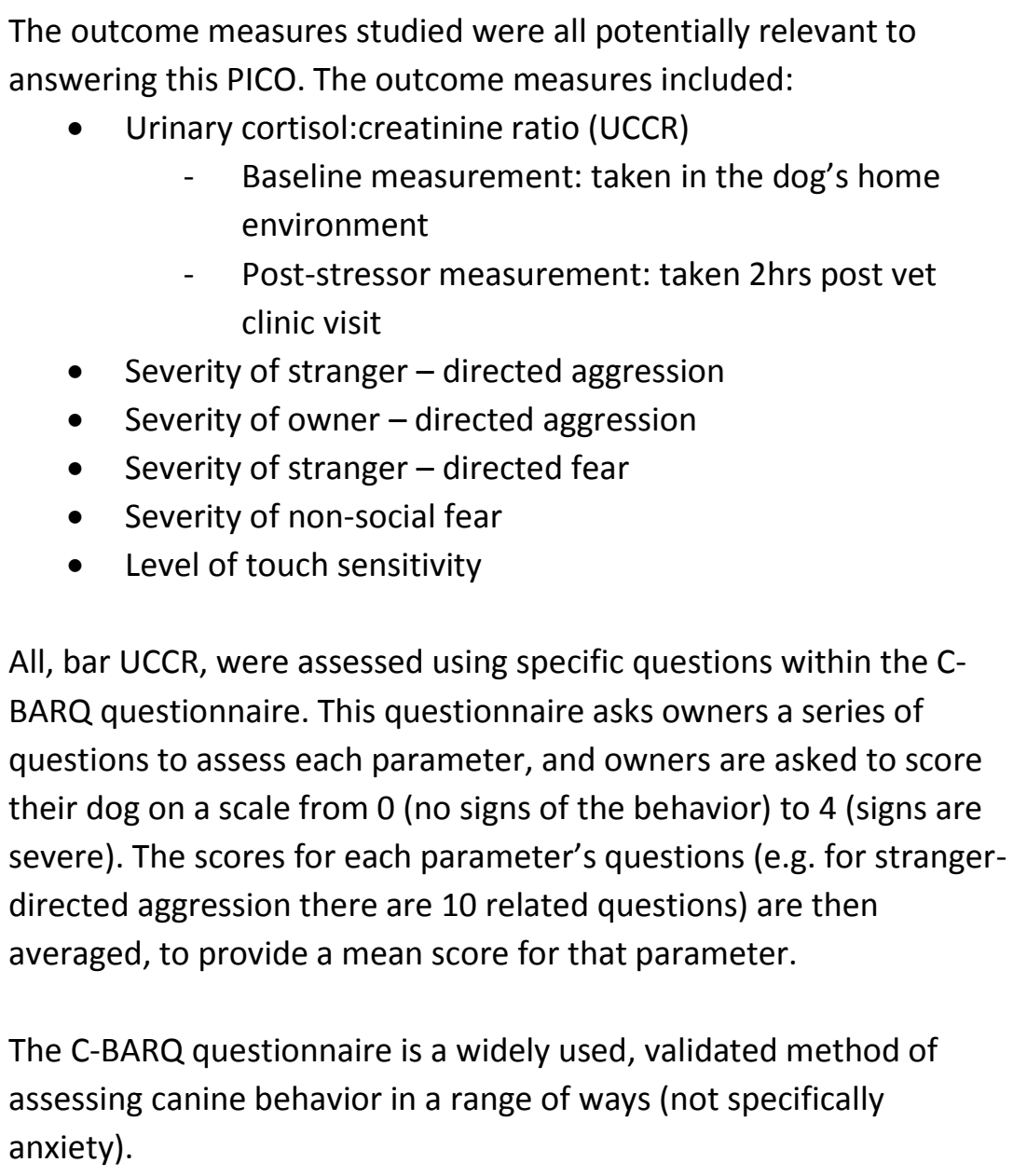 \\
\hline $\begin{array}{l}\text { Main findings: } \\
\text { (relevant to PICO question): }\end{array}$ & $\begin{array}{l}\text { UCCR: } \\
\text { - } \quad \text { Baseline UCCR of the dogs was not significantly different }\end{array}$ \\
\hline
\end{tabular}




\begin{tabular}{|c|c|}
\hline & 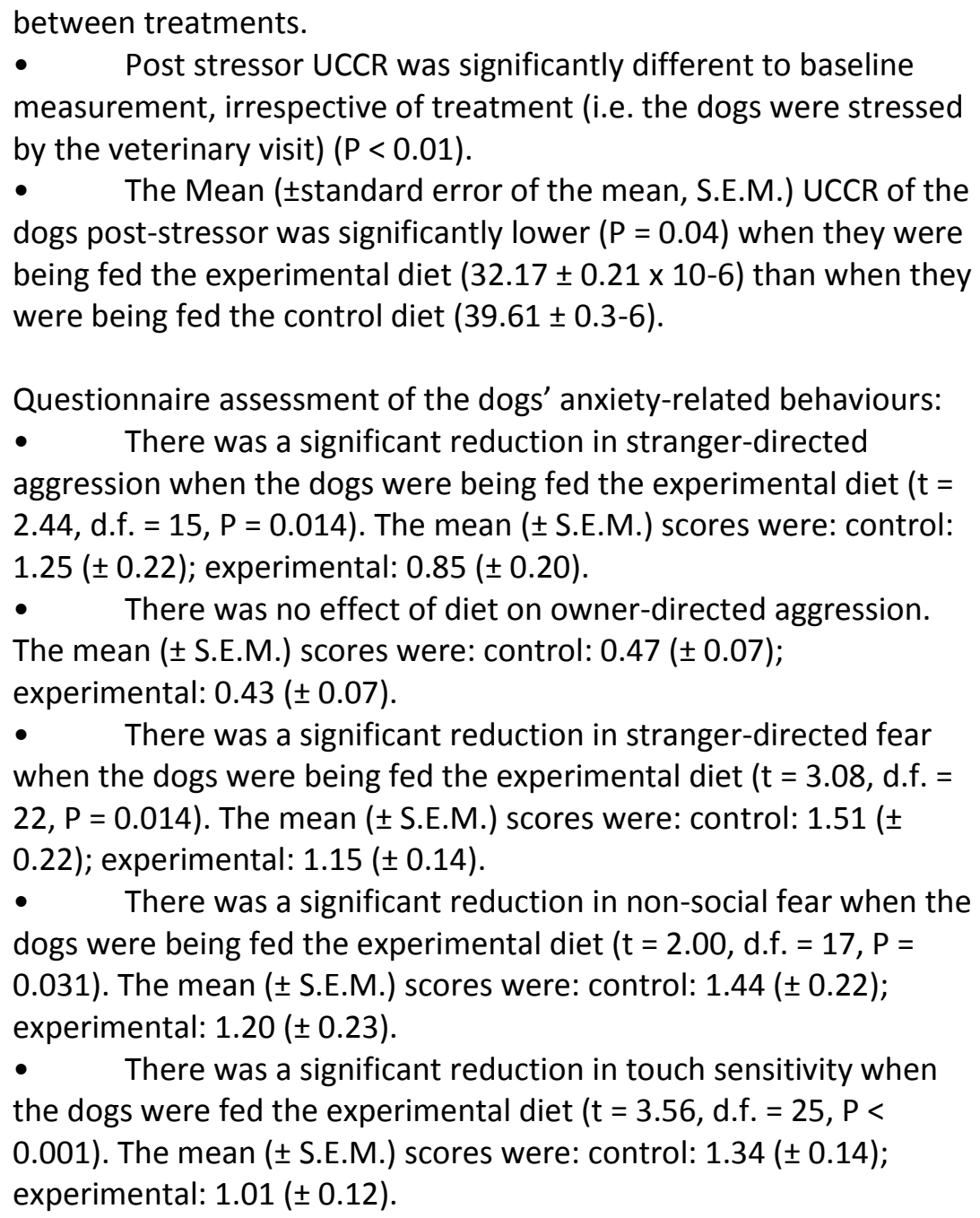 \\
\hline Limitations: & $\begin{array}{l}\text { The study was partially funded by Royal Canin. The authors do not } \\
\text { state whether Royal Canin had any input into the experimental } \\
\text { design. } \\
\text { The study was not specifically designed to study the effects of alpha- } \\
\text { casozepine on anxiety. Rather, it was set up to study the effects of a } \\
\text { commercial diet that contained alpha-casozepine and increased } \\
\text { levels of tryptophan. Thus, there was a complete confounding } \\
\text { variable when using this study to address the PICO question. } \\
\text { The diets used were not identical in all other respects, other than } \\
\text { the dietary additives. This was sufficient for a commercial aim (to } \\
\text { show the diet was beneficial) but limited interpretation of the } \\
\text { effects of any specific additive. } \\
\text { The study did not randomise the order in which the dogs received } \\
\text { the treatments. Therefore, the study is at risk of order effect biases. } \\
\text { It is not clear why this was not done as the order that the diets was } \\
\text { presented to the dogs was under the control of the experimenters } \\
\text { and the experimenters provide no explanation for why this approach } \\
\text { was taken. }\end{array}$ \\
\hline
\end{tabular}


The authors refer to preliminary data to establish that dietary additives to the diet would be fully eliminated from the body within one week, in order to justify the one week washout period.

However, it is unclear what dietary additives they are referring to as the experimental diet containing the additional dietary additive (alpha-casozepine) or increased levels of the dietary additive tryptophan was presented to all dogs in the second (post wash out period) phase of the study.

Cortisol is a non-specific measure of arousal, rather than a specific biomarker for stress. Therefore, it is possible that the dogs were excited or stimulated by a trip to the vets, rather than fearful. The authors fail to determine what the dogs' normal behavioural response is to a trip to the vets.

The C-BARQ questionnaire assessment of the dogs to determine which dogs were included in the study provides insufficient detail.

1. The C-BARQ questionnaire used is not a questionnaire that has been validated to anxiety per se. Several of the categories are specifically designed to assess fear, but some are not. Or particular relevance here is the aggressionrelated categories. Not all aggression is derived from anxiety.

2. The definition of an 'anxious dog' (i.e. that meets the inclusion criteria) was very loosely defined. Dogs were only excluded if, on all the questions asked $\left(n=32^{1}\right)$, the owner scored the dog as a 0 (no sign) to 1 (mild signs observed). Thus, a dog could be included if the owner scored it as a 2 (somewhere between mild and moderate) on just one of the questions.

${ }^{1}$ Assumes mutual exclusivity of the questions. The authors do not clarify whether one question assesses more than one parameter simultaneously.

\section{Appraisal, application and reflection}

Three peer reviewed papers were identified that either partially or fully addressed the PICO. Two of these studies (Palestrini et al., 2010; Kato et al., 2012) investigated the use of diets with added alpha-casozepine, though, in the Kato et al. (2012) study the diet was also supplemented with another compound (tryptophan) thought to have anxiolytic properties. The remaining study (Beata et al., 2007) investigated the use of a daily capsule of alpha-casozepine. The two studies focused on dietary interventions (Palestrini et al, 2010; Kato et al., 2012) used a placebo-controlled study design, whereas Beata et al. (2007) compared alpha-casozepine to another intervention (selegiline) that was already used commercially as an anxiolytic.

All of the studies focus on the potential anxiety-reducing effects of alpha-casozepine when administered in the medium to long term. Time from baseline measurement to the first and last assessment of anxiety ranged from 14-56 days (Beata et al., 2007), c.30-68/69 days (Palestrini et al. 2012) or 7 weeks (one defined timepoint) (Kato et al. 2012). The Palestrini et al. (2010) study also undertook an assessment of the dogs at the start of administering the diet (separate to an additional set of baseline measurements taken immediately before starting the diet). However, there is insufficient study detail to define the exact details 
here and the number of days that comprised this phase is uncertain. Furthermore, as no significant differences were identified between this and the pre-diet baseline measurements, it is clear that there are no studies that found a significant effect of alpha-casozepine on indices of anxiety in the short term. Further, no studies were identified that looked at the effects of alpha-casozepine to a dog shortly before (e.g. minutes to a few days) exposure to a novel, or intermittent stressor (e.g. fireworks). Thus, there is currently no research evidence to support recommending the use of alpha-casozepine to clients seeking a quick acting anxiolytic product to alleviate short term stressors in the dog's immediate or short term future.

All three of the studies that examined the effect of alpha-casozepine administration in the medium-long-term of indices of anxiety were problematic in terms of experimental design. Of the studies that looked at the effect of alpha-casozepine, the industry-sponsored study by Beata et al. (2007) offered the weakest experimental design and the authors appear unaware of this limitation as the conclusions that they draw are misleading. Equivalence and / or non-inferiority type studies in which a new treatment is compared to an existing treatment are increasingly commonplace in medical research and justified as removing the ethical issues of not treating some patients at all (or giving a placebo). Beata et al. (2007) adopt this approach, but their study design also includes a behavioural modification programme (BMP) alongside each of the anxiolytic products compared. This represents a confounding variable. As a consequence, even though their findings appear to indicate that alpha-casozepine has a similar efficacy as selegiline, based on their study design, the level of efficacy (from no effect to very effective) cannot be determined for either product as the effect of BMP is also unknown. This problem is compounded by their exclusion criteria as they systematically exclude any dogs that have already received BMP. Thus, it is not possible for the authors to justify their conclusions by the claim that, prior to starting anxiolytic therapy, these dogs had failed to respond to the BMP. Though even this appeal would be sensitive to the effects of time spent implementing a BMP on indices of anxiety reduction. Any appeal to the efficacy of alpha-casozepine would require appeal to the wider literature demonstrating an effect of selegiline per se on indices of anxiety in the dog and the inherent limitations and problems that entails. Thus, this study fails to address adequately the PICO posed in the Knowledge Summary.

Of the three studies, the Palestrini et al. (2010) most successfully set up their treatment groups to address the PICO. The two diets compared are identical other than the addition of caseinate hydrolysate (the milk protein isolate containing alpha-casozepine) and the dogs are not undergoing a behavioural modification programme. However, they fail to state the inclusion rate of the caseinate hydrolysate and the dogs were allowed to consume the diet on an ad libitum basis so individual dog exposure to the active ingredient was variable. One of the strengths of this study is that they also include a non-anxious group of dogs that are also randomly allocated to receive either the experimental or control diets. This potentially allowed them to identify whether any behavioural changes observed were due to other, non-anxiety based, properties of alpha-casozepine. However, the sample sizes utilised in this study were small to start with $(\mathrm{n}=8$ per subgroup), and they took the further, questionable, step at the end of data collection, of retrospectively removing from the main analysis, three of the dogs in the anxious group. They fail to report which of the treatment groups (experimental versus control diet) these dogs were allocated to and this means that one of these subgroups (crucial to answering the PICO) may have had as few as 5 dogs in it. Frequently, the paper moves from comparing diet groups (the aim of the study) to comparing the responses of anxious and nonanxious dogs and, therefore, fails to address the PICO at many points. There is some evidence (cortisol, reactivity evaluation form) to suggest the experimental diet reduced anxiety in anxious dogs by the end of the study, but most other physiological or behavioural parameters were either not affected by treatment or the findings are unreported. Poor data handling and reporting (see limitations) further limit the ability of the reader to draw meaningful inferences from the findings of this study. External validity is also questionable: with a captive-bred, born, reared and studied population of laboratory beagles and a maximum sample size per group of eight dogs (or lower), it is questionable how well any findings could be extrapolated to the pet population, with their varying genetic history and life time experiences.

Unfortunately, the final study (Kato et al. 2012) is also problematic in terms of addressing the PICO. In its 
defence, this industry sponsored study was not set up specifically to study alpha-casozepine but rather the effects of feeding a diet containing both alpha-casozepine and tryptophan on longer term indices of anxiety in the pet dog. Thus, the confounding variable of these additives to the diet exists for the purpose of the PICO but not for the purpose of the original study. However, the treatment diets were still not tightly controlled with the two diets varying across many dimensions other than the additives thought to reduce anxiety. Dogs were used as their own control, with an eventual sample of 28 dogs. Data handling was better within this study with relative homogeneity of the treatment effects observed: of the six outcome measures used, only one parameter showed no effect of treatment (owner - directed aggression). The other five parameters (urinary cortisol: creatinine ratio, stranger directed aggression, stranger-directed fear, non-social fear, and touch sensitivity) were all significantly improved when the dogs were fed the experimental diet. However, inclusion criteria for the study was relatively lax. If a dog scored above 1 on any one question out of circa 28 questions selected from the pre-validated C-BARQ questionnaire for being thought (by the researchers) to be potential measures of anxiety in the dog, they were included in the study. The mean values for each dog on the control diet suggests that dogs were generally scoring low across categories anyway which suggests that, in general these were not necessarily a particularly anxious population of dogs that were studied. Furthermore, the experimental design put the findings at a relatively high risk of bias. Despite the authors having experimental control over the study population, they chose to undertake an experimental design in which all dogs first received the control diet, followed by all dogs receiving the experimental diet. This makes the outcome particularly sensitive to order effects as dogs may simply have improved over time. For example, the cortisol of the dogs was lower at the second visit to the veterinary clinic. This could be because the dog had habituated to the veterinary practice (though the authors point out these dogs visited the vets regularly). Alternatively, if owners chose to participate in a trial testing diets aimed at reducing anxiety, this might alert them to the need to other information that might be used to reduce anxiety in their dogs. Furthermore, the researchers refer to a wash out period of 1 week between trials to ensure that additives have been removed, yet it is not clear what additives they are referring to as the ones in question are only included in the second phase.

In summary, whilst there is some evidence (through a shared direction of effect where a significant effect exists) across the studies that alpha-casozepine may have a clinically beneficial effect in reducing canine anxiety in the medium to longer term, the current evidence is weak and there is a need for good quality, placebo-controlled, randomised clinical trials that specifically address this compound for common anxietycausing scenarios that this biomolecule may be promoted as a potential solution for.

\section{Methodology Section}

\begin{tabular}{|c|c|}
\hline \multicolumn{2}{|l|}{ Search Strategy } \\
\hline $\begin{array}{r}\text { Databases searched and dates } \\
\text { covered: }\end{array}$ & $\begin{array}{l}\text { Pubmed (1900 - 2017); Web of Science }(1970-2017) \text {; CAB } \\
\text { Abstracts }(1983-2016)\end{array}$ \\
\hline Search terms: & $\begin{array}{l}\text { (dog OR dogs OR canine OR bitch* OR canid OR puppy OR puppies) } \\
\text { AND ("alpha casozepine" OR alfa1-casozepine OR alpha-casozepine } \\
\text { OR casein OR “milk protein" OR zylkene OR milk) AND (anxiety OR } \\
\text { anxious OR fear OR fearful OR stress OR stressed OR stressful OR } \\
\text { panic OR phobi*) }\end{array}$ \\
\hline Dates searches performed: & $11^{\text {th }}$ July 2017 \\
\hline
\end{tabular}




\section{Exclusion / Inclusion Criteria}

\begin{tabular}{|c|l|}
\hline Exclusion: & $\begin{array}{l}\text { Pre-defined exclusion criteria: non English language, popular press } \\
\text { articles }\end{array}$ \\
\hline Inclusion: & $\begin{array}{l}\text { Any comparative (control group utilised) study in which the effect } \\
\text { of alpha-casozepine on anxiety (or similar) in dogs was studied. }\end{array}$ \\
\hline
\end{tabular}

\begin{tabular}{|l|c|c|c|c|c|c|}
\hline \multicolumn{1}{|l|}{ Search Outcome } & $\begin{array}{c}\text { Number } \\
\text { of results }\end{array}$ & $\begin{array}{c}\text { Excluded - did } \\
\text { not answer } \\
\text { PICO question }\end{array}$ & $\begin{array}{c}\text { Excluded - } \\
\text { not English } \\
\text { language }\end{array}$ & $\begin{array}{c}\text { Excluded - } \\
\text { conference } \\
\text { abstract only }\end{array}$ & $\begin{array}{c}\text { Excluded - } \\
\text { duplicates }\end{array}$ & $\begin{array}{c}\text { Total } \\
\text { relevant } \\
\text { papers }\end{array}$ \\
\hline NCBI PubMed & 22 & 22 & 0 & 0 & 0 & 0 \\
\hline $\begin{array}{l}\text { Thomson } \\
\text { Reuters Web } \\
\text { of Science }\end{array}$ & 33 & 30 & 1 & 0 & 0 & 2 \\
\hline CAB Abstracts & 46 & 42 & 1 & 1 & 1 & 2 \\
\hline Total relevant papers when duplicates removed & & & & 3 \\
\hline
\end{tabular}

\section{CONFLICT OF INTEREST}

The author declares no conflict of interest.

\section{REFERENCES}

1. Beata, C. et al. (2007) Effects of alpha-casozepine (Zylkene) versus selegiline hydrochloride (Selgian, Anipryl) on anxiety disorders in dogs. Journal of Veterinary Behaviour: Clinical Applications and Research, 2 (5), pp. 175-183 http://dx.doi.org/10.1016/j.jveb.2007.08.001

2. Kato, M. et al. (2012) Effects of prescription diet on dealing with stressful situations and performance of anxiety-related behaviors in privately owned anxious dogs. Journal of Veterinary Behavior: Clinical Applications and Research, 7 (1), pp. 21-26 http://dx.doi.org/10.1016/i.jveb.2011.05.025

3. Pageat, P. (1995) Pathologie du comportement du chien. Editions du Point Veterinaire, Maisons-Alfort: $208-224$

4. Palestrini, C. et al (2010) Efficacy of a diet containing caseinate hydrolysate on signs of stress in dogs. Journal of Veterinary Behavior, 5 (6), pp. 309-317 http://dx.doi.org/10.1016/j.jveb.2010.04.004 


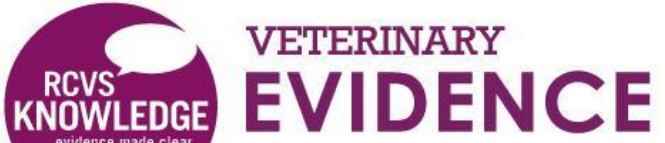 \\ ochese}

\section{Intellectual Property Rights}

Knowledge Summaries are a peer-reviewed article type which aims to answer a clinical question based on the best available current evidence. It does not override the responsibility

of the practitioner. Informed decisions should be made by considering such factors as individual clinical expertise and judgement along with patient's circumstances and owners' values. Knowledge Summaries are a resource to help inform and any opinions expressed within the Knowledge Summaries are the author's own and do not necessarily reflect the view of the RCVS Knowledge.

Authors of Knowledge Summaries submitted to RCVS Knowledge for publication will retain copyright in their work, but will be required to grant to RCVS Knowledge an exclusive license of the rights of copyright in the materials including but not limited to the right to publish, re-

publish, transmit, sell, distribute and otherwise use the materials in all languages and all media throughout the world, and to license or permit others to do so.

Authors will be required to complete a license for publication form, and will in return retain certain rights as detailed on the form.

Veterinary Evidence and EBVM Network are RCVS Knowledge initiatives. For more information please contact us at editor@veterinaryevidence.org

RCVS Knowledge is the independent charity associated with the Royal College of Veterinary Surgeons (RCVS). Our ambition is to become a global intermediary for evidence based veterinary knowledge by providing access to information

that is of immediate value to practicing veterinary professionals and directly contributes to evidence based clinical decision-making.

\section{www.veterinaryevidence.org}

RCVS Knowledge is a registered Charity No. 230886. Registered as a Company limited by guarantee in England and Wales No. 598443.

Registered Office:

Belgravia House

62-64 Horseferry Road

London SW1P 2AF 